\title{
Sexually dimorphic gene expression in the heart of mice and men
}

\author{
Jörg Isensee • Henning Witt • Reinhard Pregla • \\ Roland Hetzer • Vera Regitz-Zagrosek • \\ Patricia Ruiz Noppinger
}

Received: 21 July 2006 /Revised: 8 May 2007 / Accepted: 7 June 2007 / Published online: 24 July 2007

(C) Springer-Verlag 2007

\begin{abstract}
The prevalence and clinical manifestation of several cardiovascular diseases vary considerably with sex and age. Thus, a better understanding of the molecular basis of these differences may represent a starting point for an improved gender-specific medicine. Despite the fact that sex-specific differences have been observed in the cardiovascular system of humans and animal models, systematic analyses of sexual dimorphisms at the transcriptional level
\end{abstract}

Electronic supplementary material The online version of this article (doi:10.1007/s00109-007-0240-z) contains supplementary material, which is available to authorized users.

Funding Grants: The project was funded by the Research and Training Group 754 "Sex- and Gender-Specific Mechanisms in Myocardial Hypertrophy” (German Research Council, DFG).

J. Isensee $\cdot$ H. Witt $\cdot$ V. Regitz-Zagrosek $\cdot$ P. Ruiz Noppinger $(\bowtie)$

Center for Cardiovascular Research,

Charité Universitätsmedizin Berlin,

Hessische Straße 3-4,

Berlin, Germany

e-mail: ruiz@molgen.mpg.de

URL: http://www.charite.de/ccr/ruiz.html

J. Isensee $\cdot H$. Witt $\cdot$ V. Regitz-Zagrosek $\cdot$ P. Ruiz Noppinger

Center for Gender in Medicine,

Charité Universitätsmedizin Berlin,

Hessische Straße 3-4,

Berlin, Germany

R. Pregla $\cdot$ R. Hetzer $\cdot$ V. Regitz-Zagrosek

German Heart Institute Berlin,

Augustenburger Platz 1,

Berlin, Germany

\section{J. Isensee $\cdot$ H. Witt $\cdot$ P. Ruiz Noppinger}

Department Vertebrate Genomics,

Max Planck Institute for Molecular Genetics,

Ihnestraße 63-73,

Berlin, Germany

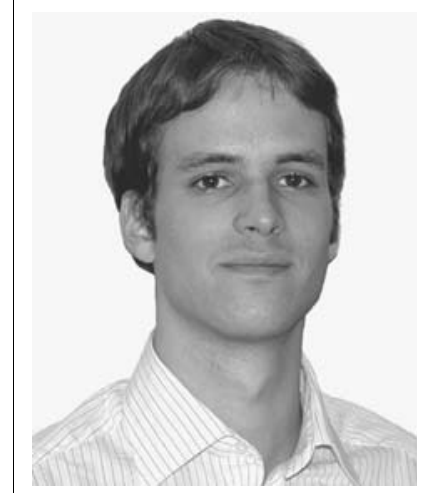

JÖRG ISENSEE

did his undergraduate work in the laboratory of Patricia Ruiz Noppinger in 2004 and is currently a $\mathrm{PhD}$ fellow in the $\mathrm{PhD}$ programme 754 "Sex- and gender-specific mechanisms in myocardial hypertrophy" funded by the German Research Council. His research focuses on molecular mechanisms of sex differences in the cardiovascular system and novel concepts of sex steroid hormone signaling in particular.

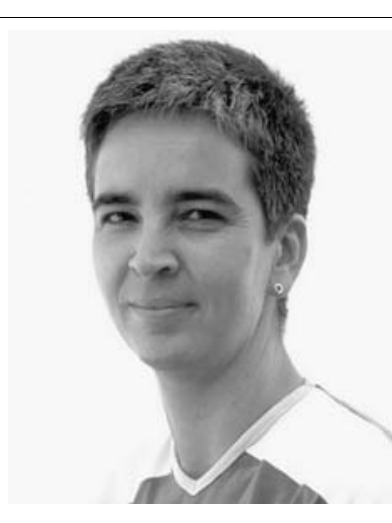

Patricia Ruiz Noppinger received her $\mathrm{PhD}$ in molecular biology at the Basel Institute for Immunology, Switzerland. She is currently a professor for "Molecular Basis of Gender Differences" at the Center for Gender in Medicine at the Charité Universitätsmedizin, Berlin. Her group focuses on functional genomics (gene expression profiling, gene trap mutagenesis and characterization of mouse models) in the context of cardiovascular diseases. in the healthy heart are missing. Therefore we performed gene expression profiling on mouse and human cardiac samples of both sexes and young as well as aged individuals and verified our results for a subset of genes using real-time polymerase chain reaction in independent left ventricular samples. To tackle the question whether sex differences are evolutionarily conserved, we also compared sexually dimorphic genes between both species. We found 
that genes located on sex chromosomes were the most abundant ones among the sexually dimorphic genes. Malespecific expression of Y-linked genes was observed in mouse hearts as well as in the human myocardium (e.g. Ddx3y, Eif2s3y and Jarid1d). Higher expression levels of $\mathrm{X}$-linked genes were detected in female mice for Xist, Timp1 and Car5b and XIST, EIF2S3X and GPM6B in women. Furthermore, genes on autosomal chromosomes encoding cytochromes of the monoxygenase family (e.g. Cyp2b10), carbonic anhydrases (e.g. Car2 and Car3) and natriuretic peptides (e.g. Nppb) were identified with sexand/or age-specific expression levels. This study underlines the relevance of sex and age as modifiers of cardiac gene expression.

Keywords Sex · Age · Gender · Heart · Microarray analysis . Gene expression

\section{Introduction}

The identification of sexual dimorphisms at transcriptome level may be a key towards a better understanding of the physiological differences between male and female and may furthermore represent a molecular basis for an improved gender-specific medicine. Recent studies using gene expression profiling made significant progress towards elucidating the molecular differences between sexes in adipose tissue, brain, kidney, liver, skeletal muscle and reproductive tissues of rodents [1-3]. However, the knowledge regarding sexual dimorphisms in humans is limited for most somatic tissues [4], and especially in the cardiovascular system, comprehensive investigations are lacking in rodents and in humans. In contrast, the number of reports identifying sex-related differences in cardiovascular phenotypes and physiology is growing. Nowadays, it is well recognised that there are significant sex differences in baseline cardiovascular function already in healthy individuals [5]. Furthermore, significant gender-specific differences have been described regarding the incidence of cardiovascular disease in human patients including left ventricular hypertrophy, coronary artery disease and cardiac remodelling after myocardial infarction $[6,7]$.

Men with heart failure die off at a faster rate then women, regardless of treatment. As the cardio-protective effect of female sex can be found predominantly in premenopausal, but not postmenopausal women [5], estrogens are in the main focus of researchers to decipher the molecular basis of sex differences in cardiovascular disease. The biological effects of steroid hormones are classically mediated by nuclear receptors acting as ligand-activated transcription factors that bind to specific response elements located in the promoters of target genes or tether to transcription factor complexes that contact DNA at alternative sites $[8,9]$. In addition, a large body of evidence indicates that steroid hormones exert rapid non-genomic effects including the activation of MAP kinase pathways [10]. Therefore, genomic and non-genomic actions of sex steroid hormones may converge on the regulation of target genes by modulating the activity of several transcription factors $[9,10]$.

Estrogen receptors $(E R \alpha$ and $E R \beta)$ are expressed in endothelial cells, vascular smooth muscle cells and in the myocardium of both sexes [6]. Additionally, androgen and progesterone receptors have been identified in the vasculature and myocardium of several species but have received less attention in the context of cardiovascular physiology. In animal models, estrogen modulates the response to pressure overload [11], ischaemia and reperfusion injury [12], vascular injury [13] and atherosclerosis [14]. Moreover, estrogen appears to play a protective role in the hypertrophic response of the heart to $\mathrm{Ca}^{2+}$ dysregulation [15] Although the direct effects of estrogen are well characterised for some tissues (e.g. the uterus and the mammary gland), estrogen receptor target genes in the heart have only been characterised to some extent using isolated cellular systems in vitro [6]. Furthermore, the molecular mechanisms of steroid hormone action might be indirect by modulating the release of non-steroidal hormones as it has been shown for growth hormone (GH). GH is released from the anterior pituitary in a cyclical manner with high amplitudes in males and with smaller amplitudes and higher pulse frequencies in females. Indeed, GH is a major determinant of sex differences in pubertal body growth rates and sex-specific gene expression in the rodent liver $[2,16,17]$ by a mechanism involving the transcription factor signal transducer and activator of transcription $5 \mathrm{~b}$ (Stat5b) [16].

In addition to the effects mediated by sex-steroid hormones, the expression and regulation of sex chromosomal genes clearly contribute to sexual dimorphisms [18]. To restore balanced expression of X-linked genes between sexes, gene dosage compensation mechanisms have evolved [19]. In females, large parts of one X-allele are silenced by $\mathrm{X}$-inactivation reducing gene dosage to the male level. However, some X-linked genes escape Xinactivation and are therefore expressed from both X-alleles in females [20]. Newer findings have revealed that the global balance of diploid gene expression may be established by up-regulation of X-chromosomal genes from the active allele in both sexes. On average, the genes on the single $\mathrm{X}$-allele give rise to as many transcripts as genes on autosomal chromosomes, suggesting a twofold upregulation of X-linked genes [19].

On the other hand, higher expression levels of X-linked genes in females might be compensated by the expression 
of functionally equivalent Y-linked genes in males. The male-specific region of the human $\mathrm{Y}$ chromosome contains $\mathrm{X}$-transposed, X-degenerated and ampliconic segments, respectively [21]. Beside the ampliconic region that encodes around 100 genes with testis-restricted expression, homologues of 29 different X-linked genes are localised in the X-degenerated and the X-transposed region. Whether protein isoforms encoded by these Y-linked genes are involved in the development of sexual dimorphisms in somatic tissues, however, is still unknown. Notably, only 23 protein-coding genes have been annotated on the murine Ychromosome so far, underlying that sexual dimorphisms of sex-chromosome-linked genes might be species-specific.

Animal studies as well as clinical data suggest that gender-specific differences in the cardiovascular system are mainly caused by the action of hormones [5]. As sex steroids and GHs exert their biological effects via nuclear hormone receptors or other transcription factors at transcriptional level, we assumed that sexual dimorphisms in cardiac gene expression may be observed already in the healthy condition and at a young age. In our study, we therefore aimed to identify evolutionary conserved sexual dimorphisms in the heart of healthy young and aged mice as well as human donors.

\section{Materials and methods}

Mouse and human tissue samples

C57BL/6J mice were obtained from Harlan-Winkelmann and kept under standardised SPF conditions and 12-h-light/ 12-h-dark cycle with free access to food and water. Animal housing, care and applications of experimental procedures complied with the Guide for the Care and Use of Laboratory Animals of the Government of Berlin, Germany, and are in accordance to the recommendations of the Society for Laboratory Animal Science (GV-SOLAS) and the Federation of European Laboratory Animal Science Associations (FELASA). For microarray analysis, mice were killed at 2 (six males and six females) and 8 (six males and six females) months of age, respectively. For real-time polymerase chain reaction (QPCR), left ventricles (including the ventricular septum) were isolated from females at different stages of the oestrous $(n=8$ at the proestrus and $n=8$ at the diestrus) and from males $(n=8)$ at 3 months of age, respectively. To asses the oestrous cycle stage in females, vaginal smears were examined once a day [22]. Animals with at least two consecutive cycles and at a defined stage underwent cervical dislocation at 6 P.M. Samples were withdrawn immediately and washed in ice-cold Hank's balanced salt solution, flash-frozen in liquid nitrogen and stored at $-80^{\circ} \mathrm{C}$.
Human left ventricular myocardial samples were obtained from explanted donor hearts of $<40$-year-old women $(n=3),<40$ years old men $(n=6), 50-65$-year-old women $(n=7)$ and 50-65-year-old men $(n=7)$ at the German Heart Institute Berlin (DHZB). Human donors presented no signs of cardiac disease and normal ECG, echocardiography and laboratory parameters. Morphological or histological abnormalities could not be found. The investigation conforms to the principles outlined in the Declaration of Helsinki.

Total RNA of individual mouse and human samples was isolated in parallel using the standard TRIzol ${ }^{\circledR}$ (Invitrogen) method according to the manufacturer's protocol. The concentration and integrity of total RNA was measured using a 2100 Bioanalyzer (Agilent). Aliquots of mouse and human RNA samples of each age group were pooled for microarray analysis. For QPCR analysis RNA samples were analysed individually. All RNAs were saved before pooling.

Gene expression analysis

For reverse transcription (Superscript III, Invitrogen) in the presence of cyanine-coupled deoxycytidine triphosphate (dCTP; Cy3 or Cy5; Amersham), $50 \mu \mathrm{g}$ of total RNA were used in a $30-\mu 1$ reaction. Labelled complementary DNAs (cDNAs) were combined with $380 \mu \mathrm{l}$ TE $(10 \mathrm{mM}$ Tris, $1 \mathrm{mM}$ ethylenediamine tetraacetic acid), $20 \mu \mathrm{g}$ mouse or human Cot1 DNA and $20 \mu \mathrm{g}$ Oligo(dA) and purified with a Microcon YM-30 column (Millipore). Samples were vacuum-centrifuged and resuspended in $7.5-\mu 1$ nucleasefree water, 2.5- $\mu$ l deposition control targets (Agilent) and $15-\mu 1$ DIG hybridisation buffer (Roche). Denatured samples $\left(98^{\circ} \mathrm{C}, 2 \mathrm{~min}\right)$ were hybridised on cDNA microarrays (Agilent) in a humidified chamber at $42^{\circ} \mathrm{C}$ for $15 \mathrm{~h}$. Four independent experiments were carried out for each age group using exchanged dye-labelled RNA probes (dyeswap). After washing, microarray slides were scanned using a microarray scanner (G2565BA, Agilent) and image analysis was performed with the Feature Extraction software 7.1.1 (Agilent).

\section{Data analysis}

For cDNA microarrays log transformed ratios were analysed using the Significance Analysis of Microarrays (SAM) [23]. For comparison of gene lists of different experiments genes identified by SAM with a false discovery rate (FDR) $<5 \%$ and a fold-change $>2$ were considered as significantly deregulated. Mouse and human microarray data are available online at the GEO database (GSE4793 and GSE4795). Affymetrix datasets (HgU133 Plus 2.0 array) of human myocardial samples from healthy 
organ donors ( $n=7$ men and women, respectively) were downloaded as MAS5.0 text files from the CardioGenomics website (Genomics of Cardiovascular Development, Adaptation, and Remodelling. NHLBI Program for Genomic Applications, Harvard Medical School. URL: http://www. cardiogenomics.org). Further analysis was applied to probes with significant hybridisation signals (detection $p$ value $<0.05$ ) in at least six out of seven samples in at least one of the sexes. Signal intensities were $\log$ transformed and analysed using SAM. Genes with FDR $<5 \%$ and foldchange $>2$ were considered as significantly deregulated. For comparison of gene lists between different experiments gene IDs were mapped to the corresponding UniGene clusters by the online tool KARMA (Keck ARray Manager and Annotator).

To interpret the relevance of sexually dimorphic genes, their overrepresentation in different GeneOntology (GO) categories and their chromosomal enrichment was determined using the web-based DAVID tool (Database for Annotation Visualization and Integrated Discovery, National Institute of Allergy and Infectious Disease) [24, 25]. Fisher's Exact $t$ test was applied to determine whether the proportion of genes in each GO category (level 5) or chromosome differed between the sexually dimorphic genes and the genes present on the microarray.

\section{Quantitative QPCR}

Total RNA was reverse transcribed using the MultiScribe ${ }^{\mathrm{TM}}$ RT kit (Applied Biosystems) and random hexamers. Subsequently, QPCR reactions were conducted in triplicate using SYBR-Green I master mix (Applied Biosystems) and $10 \mathrm{ng}$ cDNA as template. No template and no reverse transcriptase controls were included and products were analysed by gel electrophoresis. PCR efficiency was determined for single reactions using DART-PCR Version 1.0 [26], and mean PCR efficiency of gene-specific reactions was used for data analysis. Normalisation and error propagation were calculated as described at the geNORM website [27]. The relative quantity of a specific transcript was calculated as $Q=E^{\wedge}(\operatorname{Min}($ mean $\mathrm{Ct}$ of all samples)-Ct), whereas $E$ represents the mean PCR efficiency. Three different housekeeping genes (Mouse: Hprt1, Gapdh, Rpl13A; Human: HPRT1, GAPDH, 18S RNA) were assayed, and a normalisation factor was calculated from the geometric mean of their expression levels. Normalised expression levels of target genes were calculated by dividing the corresponding relative quantity by the normalisation factor. Statistical significance was assessed using a two-tailed $t$ test assuming unequal variance of the biological replicates. Intron-spanning gene-specific primers were designed using the Primer3 software [28] and sequences are provided in Supplementary Table 4.

\section{Results}

Identification of genes with sexually dimorphic expression

To identify genes with sex-biased expression in the human and mouse heart, we used a cDNA microarray approach (Fig. 1). Labelled cDNAs were hybridised on microarrays containing either 8,692 mouse $(7,134$ UniGene cluster) or 13,169 human cDNA clones (7,782 UniGene cluster), respectively. The microarrays contained an overlap of 3,009 orthologue genes as determined by mapping the corresponding UniGene clusters to the HomoloGene resource. To differentiate between the pre- and postmenopausal status of human female donors, we arranged the human myocardial tissue samples into two age groups, one containing donors younger than 40 years (four men and three women) and a second one with donors between 50 65 years of age (five men and five women). Furthermore, we compared the gene expression patterns between males and females of 2 and 8 months old mice ( $n=6$ per group), respectively.

A total of 90 genes in 2 months old and 33 genes in 8 months old mice were considered deregulated between sexes (fold-change $>2$, FDR $<5 \%$; expression data are provided in Supplementary Table 1). Some more deregulated genes (93 in young and 125 in aged donors) were detected using the Agilent platform in the human myocardium (Figs. 1 and 2b). In total, 13 genes in mice (Fig. 2a) and 14 in humans (Fig. 2b) were identified to be expressed in a sex-dependent manner irrespective of age. In addition, we analysed a public dataset (Cardiogenomics) containing myocardial expression data of seven male and seven female healthy donors, respectively. Analysis of this dataset revealed that $37 \%$ of all probes had a significant present call in at least six out of the seven samples in at least one of the sexes. A total of 16 genes with sex-biased expression was detected using this platform (Figs. 1 and 2c).

Notably, five genes (EIF1AY, JARID1D, USP9Y, DDX3Y and RPS4Y1) encoded on the $Y$ chromosome were detected with human male-specific expression using both platforms. In a cross-species comparison we found eight genes showing sex-biased expression in mice as well as in humans including $\mathrm{X}$ inactivation-specific transcript (Xist/XIST), carbonic anhydrase 3 (Car3/CA3), keratin 8 (Krt2-8, KRT 8), tissue inhibitor of metalloproteinase 1 (Timp1/TIMP1), natriuretic peptide precursor B, serpin peptidase inhibitor A3 (Serpina3n/SERPINA3), DEAD (Asp-Glu-Ala-Asp) box polypeptide 3 (Ddx3y/DDX3Y) and jumonji (Jarid1d/SMCY; Table 1).

To confirm our results by an independent approach, we determined the expression levels of several genes in all samples used for the microarray analysis individually by QPCR. We found that in many cases their expression 


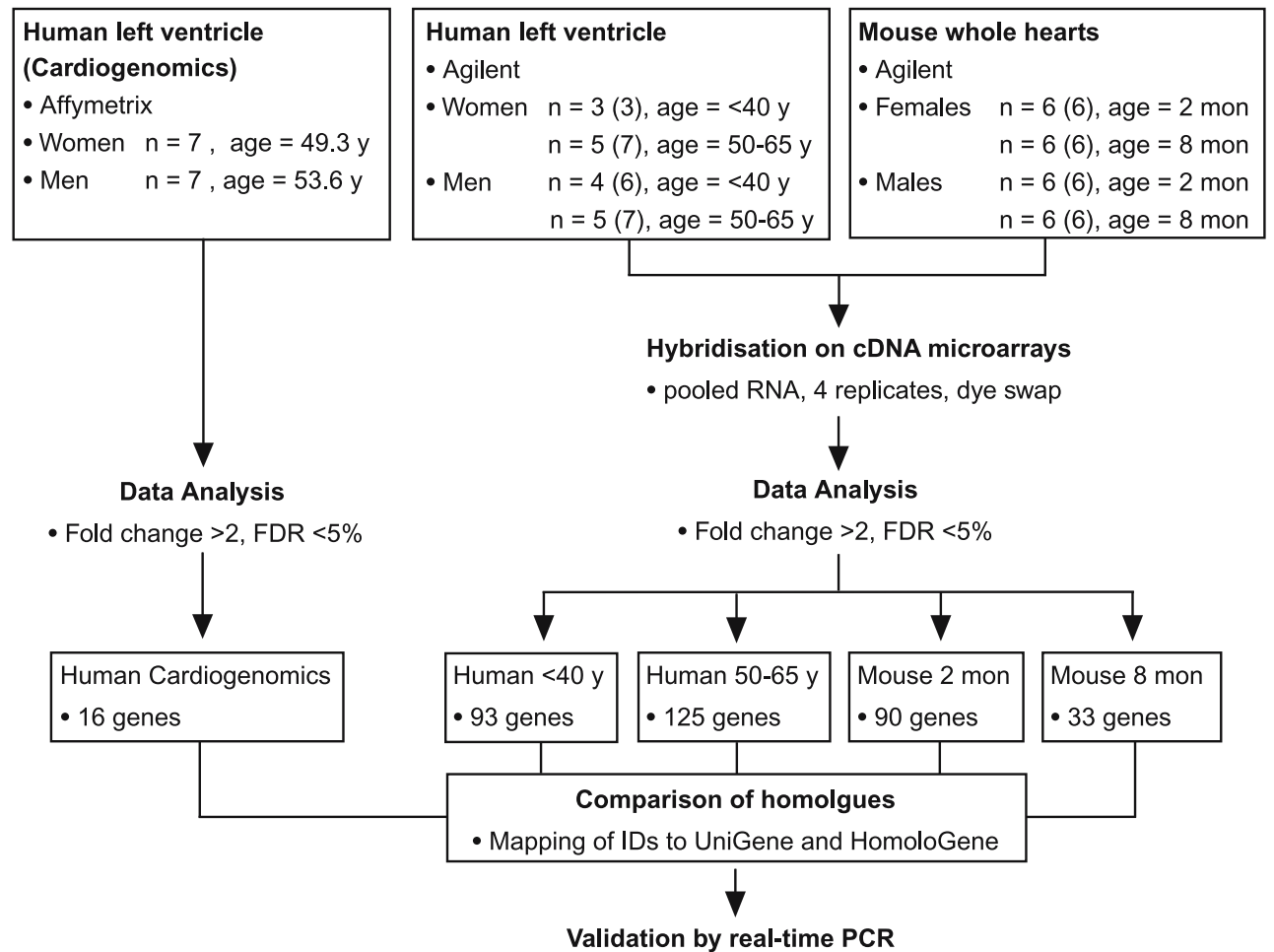

Fig. 1 Experimental design to screen for genes with sex-biased expression in the heart of mice and human donors. Total RNA was isolated from mouse whole heart samples and from myocardial tissue of human donors. Cyanine dye labelled cDNAs generated from pooled RNAs were hybridised on Agilent cDNA microarrays. In addition, human myocardial expression datasets were downloaded from CardioGenomics and filtered for sex-biased genes. Candidate gene lists were compared to identify sexual dimorphisms in young as well as

correlates significantly with sex and/or age and could therefore validate the results obtained by microarray analysis (Figs. 3 and 4). To asses whether the expression of these genes is affected by the oestrous cycle, we analysed left ventricular samples of an independent group of female mice at different stages of the oestrous in comparison to male littermates. Notably, we could not detect statistically significant expression differences during the oestrous cycle for the six genes analysed (Figs. 3 and 4).

\section{Differential expression of $\mathrm{X}$ - and Y-linked genes}

Genes located on sex chromosomes were the most abundant ones among the identified sexually dimorphic genes and represent reliable controls of our experimental setup. In all datasets, genes on the Y-chromosome were significantly overrepresented ( $p<0.05$; Table 2 and Fig. 2). Male-specific expression was observed for the Y-linked genes Jarid1d, Ddx3y, and Eif2s3y in mouse hearts (Fig. 2a) and for JARID1D, DDX3Y, EIF1AY, RPS4Y1, USP9Y, UTY, ZFY, PRKY, CYorf14, CYorf15A, CYorf15B and CD24L4 in the human myocardium (Fig. 2b,c). In addition, in 8 months old mice genes on the $\mathrm{X}$-chromosome were overrepresented aged individuals and both species and platforms. Expression levels of several candidate genes were quantified individually by real-time PCR (QPCR) in the same samples used for microarray analysis and in left ventricular samples from female mice at different stages of the oestrous as well as from males ( $n=8$ per group). Numbers of individuals analysed by QPCR are shown in brackets. FDR, false discovery rate; $y$, years; mon, months

including Xist, Gla, Timp1 and Car5b (Fig. 2b). In aged human samples, the X-linked genes XIST, TIMP1 and GPM6B were found to be upregulated in females (Fig. 2c).

Differential expression of genes on autosomal chromosomes

Beside $\mathrm{X}$ - and Y-linked genes we detected genes on autosomal chromosomes with sex-biased expression. In mice we found an overrepresentation of genes encoded on chromosome 6 and in humans on chromosomes 1 and 8 , respectively (Table 2). Interestingly, carbonic anhydrases of the $\alpha$-subgroup (Car1-3) localised on human chromosome 8 and on mouse chromosome 3 were identified with sexbiased expression in both species (Table 1). By QPCR we confirmed higher expression levels of Car3 in whole heart samples of 2 months old female mice (threefold) as well as in ventricular samples of 3 months old ones (Fig. 3a,b). This sexual dimorphism appeared to be independent of the oestrous cycle (Fig. 3b). QPCR quantification of the human orthologue CA3 revealed a similar trend only in the group of older human donors (Fig. 3c). We then quantified the expression of Car2 in murine hearts and found that this 
a
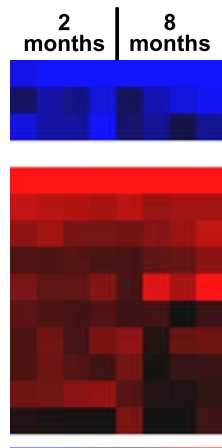

+ Male/Female -

b

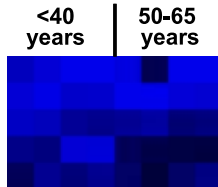

Fold-change FDR

$\begin{array}{llll}4.3 & 5.2 & 0.2 & 0.1 \\ 3.3 & 2.7 & 0.2 & 0.1\end{array}$

$\begin{array}{llll}3.5 & 2.1 & 0.2 & 0.1\end{array}$

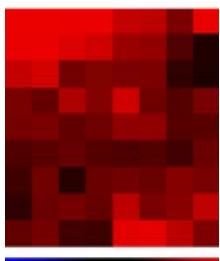

$\begin{array}{llll}-6.2 & -3.6 & 0.2 & 0.1\end{array}$

$\begin{array}{llll}-4.9 & -2.1 & 0.2 & 0.1\end{array}$

$\begin{array}{llll}-3.1 & -2.0 & 0.2 & 0.1 \\ -2.6 & -2.5 & 0.2 & 0.1\end{array}$

$\begin{array}{llll}-2.3 & -2.3 & 0.2 & 0.1 \\ -2.0 & -2.0 & 0.2 & 0.1\end{array}$

$\begin{array}{llll}-2.3 & -2.3 & 0.2 & 0.1 \\ -2.0 & -2.0 & 0.2 & 0.1\end{array}$

$\begin{array}{llll}-2.0 & -2.4 & 0.2 & 0.1\end{array}$

$\begin{array}{llll}-2.0 & -3.1 & 0.2 & 0.1\end{array}$

$\begin{array}{llll}-2.0 & -3.7 & 0.2 & 0.1\end{array}$ $\begin{array}{llll}6.3 & 6.4 & 0.2 & 0.1 \\ 4.3 & 5.2 & 0.2 & 0.1\end{array}$

$\begin{array}{llll}3.5 & 2.0 & 0.2 & 0.1\end{array}$

\section{Human (Agilent)}

\section{ID}

AF000986

AF000987

$\mathrm{Al} 281103$

D87072

M58459

AY017349

U42031

B1560455

M26326

AW608422

BC004897

U53445

M26602
Gene

USP9Y

EIF1AY

GSTT1

JARID1D

DHRS9

FKBP5

HSPA5

KRT18

POSTN

$\mathrm{CA} 3$

DOC1

DEFA1

ITGB1
Description

Ubiquitin specific protease 9

Eukaryotic translation initiation factor $1 \mathrm{~A}$

Glutathione S-transferase theta 1

Jumonji, AT rich interactive domain 1D

Ribosomal protein S4

Dehydrogenase/reductase member 9

FK506 binding protein 5

Heat shock $70 \mathrm{kDa}$ protein 5

Keratin 18

Periostin, osteoblast specific factor

Carbonic anhydrase III, muscle specific

Downregulated in ovarian cancer 1

Defensin, alpha 1

Integrin, beta 1

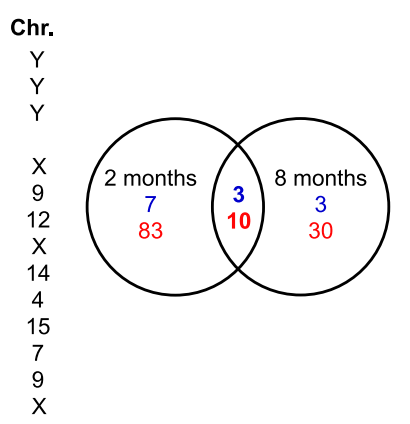

+ Male/Female -

C

\section{Human (Affymetrix)}

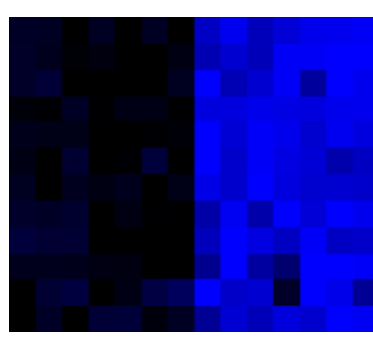

Fold-

change FDR ID Gene

$34.3 \quad 2.5$ 206624_at USP9Y

26.82 .5 230760_at ZFY

$16.2 \quad 2.5$ 207063_at CYorf14

$411.8 \quad 2.5 \quad 204409$ s at EIF1AY

55.62 .5 201909_at RPS4Y1

8.02 .5 214131_at CYorf15B

62.42 .5205000 at DDX3Y

13.72 .5 206700_s_at JARID1D

$\begin{array}{lll}10.0 & 2.5 & 211149 \text { at UTY }\end{array}$

5.52 .5 236694_at CYorf15A

2.13 .4 206279_at PRKY

5.12 .5 209771_x_at CD24L4

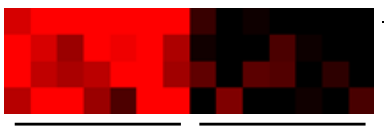

$-322.62 .5 \quad 224590$ at $\quad$ XIST

$-2.0 \quad 2.5 \quad 227904$ at $\mathrm{AZI} 2$

$\begin{array}{lll}-9.2 & 3.4 & 205767 \text { at } \\ -2.0 & 3.4 & 209169+a t\end{array}$

$-2.0 \quad 3.4 \quad 209169 \_$at $\quad$ GPM6B

Female

Male

Fig. 2 Candidate genes identified by microarray approaches. a False colour representation of the 13 overlapping genes (see also intersection in the Venn diagram) identified with sex-biased expression in 2 as well as in 8 months old mice. Fold-changes were calculated from four technical replicates using pooled total RNA isolated from male and female whole mouse hearts of both age groups ( $n=6$ per group). Numbers of genes identified with sex-biased expression in each group (90 and 33, respectively) are shown in the Venn diagram. b False colour representation of the 14 overlapping genes (see also intersection in the Venn diagram) identified with sex-biased expression in human left ventricular samples of both age groups. Fold-changes were calculated from four technical replicates using pooled total RNA

$\begin{array}{lc}\text { Description } & \text { Chr } \\ \text { Ubiquitin specific protease 9 } & \text { Y } \\ \text { Zinc finger protein } & \text { Y } \\ \text { Chromosome Y open reading frame 14 } & \text { Y } \\ \text { Eukaryotic translation initiation factor 1A } & \text { Y } \\ \text { Ribosomal protein S4 } & \text { Y } \\ \text { Chromosome Y open reading frame 15B } & \text { Y } \\ \text { DEAD (Asp-Glu-Ala-Asp) box polypeptide 3 } & \text { Y } \\ \text { Jumonji, AT rich interactive domain 1D } & \text { Y } \\ \text { Ubiquitously transcribed tetratricopeptide } & \text { Y } \\ \text { Chromosome Y open reading frame 15A } & \text { Y } \\ \text { Protein kinase } & \text { Y } \\ \text { CD24 molecule-like 4 } & \text { Y } \\ & \\ \text { X (inactive)-specific transcript } & \text { X } \\ \text { 5-azacytidine induced 2 } & 3 \\ \text { Epiregulin } & 4 \\ \text { Glycoprotein M6B } & \text { X }\end{array}$

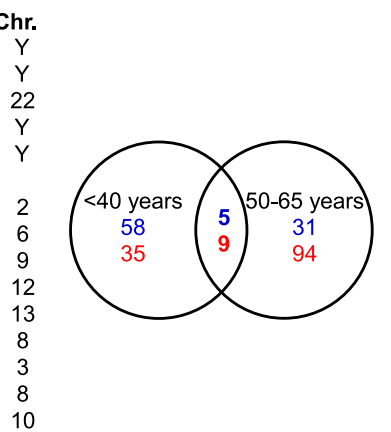

isolated from three to five samples per group. Numbers of genes identified with sex-biased expression in each age group (93 and 125, respectively) are shown in the Venn diagram. c False colour representation of the 16 genes identified in the Cardiogenomics dataset with sexbiased expression in myocardial tissue of male (mean age $=53.6$ years) and female (mean age $=49.3$ years) human donors ( $n=7$ per group). Note that for some genes sex-biased expression was detected in both species (e.g. Ddx3y and Jarid1d) as well as in both platforms (USP9Y and RPS4Y1). Shades of red represent female-biased expression and blue, male-biased expression in individual samples (FDR $<5 \%$, foldchange $>2$ ) 
Table 1 Cross-species comparison of genes with sex-biased expression in mice as well as in humans

\begin{tabular}{|c|c|c|c|c|c|c|c|c|}
\hline \multicolumn{2}{|l|}{ Mouse } & \multicolumn{3}{|l|}{ Human } & \multirow{2}{*}{$\begin{array}{l}\text { Homolo- } \\
\text { Gene ID }\end{array}$} & \multirow[t]{2}{*}{ Gene } & \multirow[t]{2}{*}{ Chr. } & \multirow[t]{2}{*}{ Protein } \\
\hline $\begin{array}{l}2 \text { months } \\
\text { (Agilent) }\end{array}$ & $\begin{array}{l}8 \text { months } \\
\text { (Agilent) }\end{array}$ & $\begin{array}{l}<40 \text { years } \\
\text { (Agilent) }\end{array}$ & $\begin{array}{l}\text { 50-65 years } \\
\text { (Agilent) }\end{array}$ & $\begin{array}{l}\text { Affy- } \\
\text { metrix }\end{array}$ & & & & \\
\hline 21.3 & 56.5 & - & - & 62.4 & 55839 & $\begin{array}{l}\text { Ddx3y/ } \\
\text { DDX3Y }\end{array}$ & $\mathrm{Y}$ & $\begin{array}{l}\text { DEAD box } \\
\text { polypeptide } 3\end{array}$ \\
\hline 6.0 & 8.7 & 3.5 & 2.0 & 13.7 & 55838 & $\begin{array}{l}\text { Jarid1d/ } \\
\text { JARID1d }\end{array}$ & $\mathrm{Y}$ & Jumonji (SMCY) \\
\hline-79.3 & -81.9 & - & - & 322.6 & - & Xist/XIST & $\mathrm{X}$ & $\begin{array}{l}X \text { inactivation- } \\
\text { specific } \\
\text { transcript }\end{array}$ \\
\hline- & -2.7 & - & -17.2 & - & 49182 & $\mathrm{Nppb/NPPB}$ & $4 / 1$ & $\begin{array}{l}\text { Natriuretic peptide } \\
\text { precursor B }\end{array}$ \\
\hline-3.0 & - & -2.0 & -2.0 & - & 31298 & Car3/CA3 & $3 / 8$ & $\begin{array}{l}\text { Carbonic } \\
\text { anhydrase } 3\end{array}$ \\
\hline- & -2.7 & - & -2.0 & - & 36321 & $\begin{array}{l}\text { Timp1/ } \\
\text { TIMP1 }\end{array}$ & $\mathrm{X}$ & $\begin{array}{l}\text { Tissue inhib. of } \\
\text { metalloproteinase } \\
1\end{array}$ \\
\hline-2.6 & - & - & -2.0 & - & 55643 & $\begin{array}{r}\text { Krt2-8/ } \\
\text { KRT8 }\end{array}$ & $15 / 12$ & Keratin 8 \\
\hline- & -2.2 & -2.0 & - & - & 40658 & $\begin{array}{l}\text { Serpina3n/ } \\
\text { SERPINA3 }\end{array}$ & $12 / 14$ & $\begin{array}{l}\text { Serpin peptidase } \\
\text { inhibitor A3 }\end{array}$ \\
\hline
\end{tabular}

To identify orthologue genes, probe identifiers were mapped to the HomoloGene resource (FDR $<5 \%$, fold-change $>2$ ). Fold-changes, gene IDs, chromosomal localization and gene products are given. Note that Jarid1d showed a male-biased expression in both species and both platforms irrespectively of age.

gene appears to be significantly upregulated with age in both sexes, although predominantly in females (Fig. 3d). Increased expression of CA2 in older individuals was also observed in human samples, whereas the fold-changes where smaller (Fig. 3f). In addition, a twofold higher expression of the X-linked Car5b gene was found in female mice of both ages (Fig. 2a).

Several cytochromes of the monoxygenase family were detected with higher expression levels in the heart of female mice. The differential expression of Cyp2b10 found using cDNA microarrays (2.7-fold, Fig. 2a) was confirmed by QPCR (threefold, Fig. 3g). Interestingly, Cyp2b10 expression was significantly higher in the 8 months old mice compared to the younger ones and quantification of the human orthologue (CYP2B6) revealed a similar trend (Fig. 3i). Female-biased expression of Cyp2b10 was also observed in the left ventricle of 3 months old mice (Fig. 3h), but the fold-change was smaller than in whole hearts. Furthermore, we detected Cyp2a4 (threefold) and Cyp2f2 (3.7-fold) being up-regulated in 2 months old as well as Cyp2b9 in 8 months old female mice (Supplementary Table 1). In addition, in myocardial samples obtained from <40-year-old human donors, we identified CYP4B1 with female-biased and CYP2J2 with male-biased expression (Supplementary Table 1).
Natriuretic peptides have been discussed earlier in the context of sex-biased gene expression in the heart [29]. We found female-biased expression of natriuretic peptide precursor B (Nppb) in old mice (2.7-fold) as well as in aged human donors (17.2-fold) (Table 1) and both could be verified by QPCR (Fig. 4d,f). Interestingly, in 2 as well as in 3 months old mice, a sexual dimorphism of Nppb expression could not be detected (Fig. 4d,e). Furthermore, we detected higher expression levels of Nppa in young female mice compared to males, although the expression differences were rather small (1.4-fold; Fig. 4a).

Finally, another gene with sex-biased expression was the orphan nuclear receptor Nr4a1 (Nur77), which was detected in female mice of both ages with a twofold higher expression than in males (Fig. 2a). We verified these results in young females by QPCR (4.5-fold), and a similar trend was observed in the older ones (1.5-fold) (Fig. 4g). Nr4a1 was found to be significantly down-regulated in older mice, suggesting that this sexual dimorphism might be more pronounced in younger individuals. This difference could, however, not be detected in left ventricular mouse (Fig. 4h) nor human (Fig. 4i) samples.

To provide insights about the functional relevance of sexual dimorphisms identified by microarray experiments in mice and humans, the data obtained was analysed for 

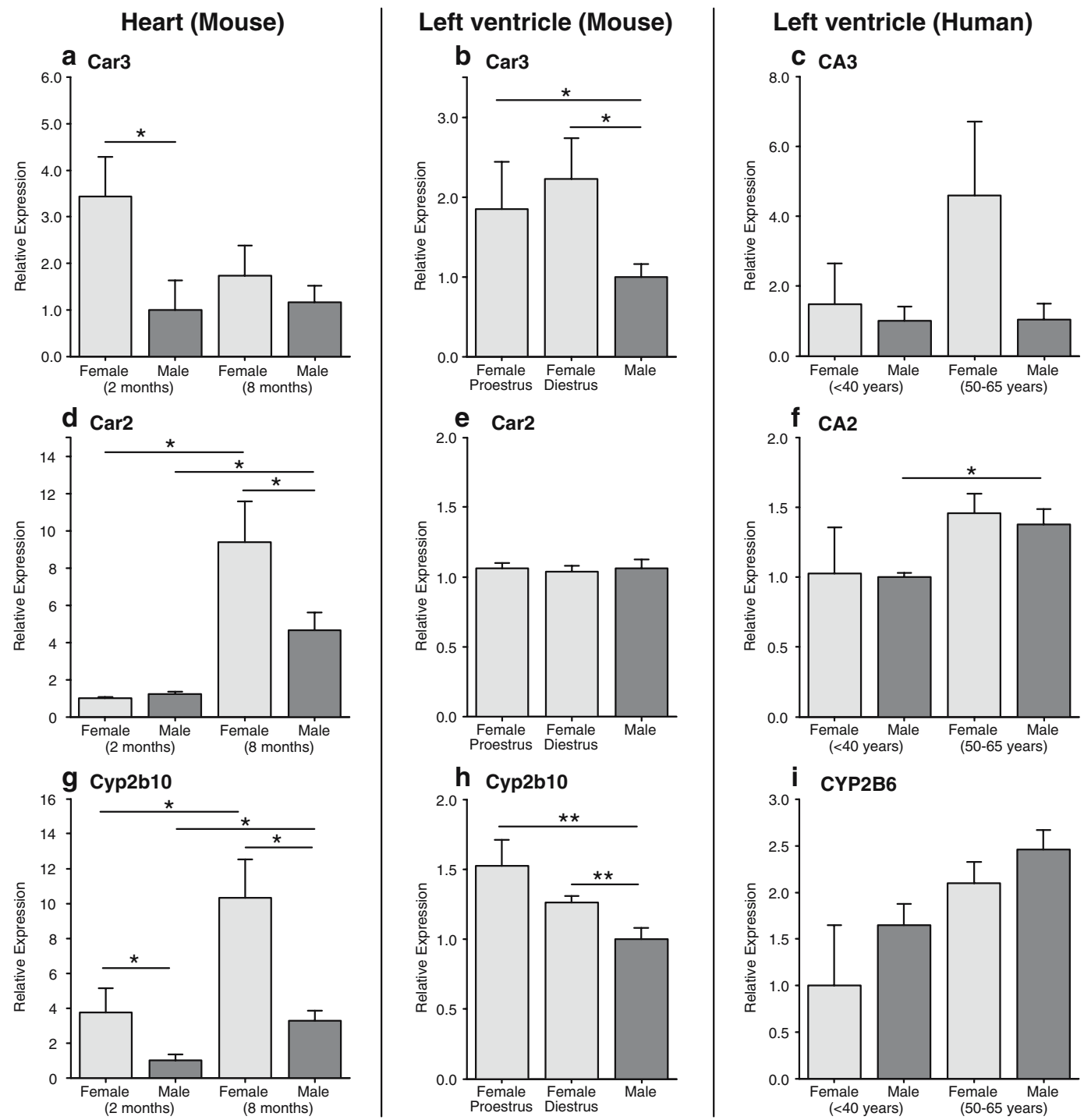

Fig. 3 Analysis of sex-biased gene expression of carbonic anhydrase 3 (Car3), Car2 and cytochrome P450 2b10 (Cyp2b10) in individual samples. The expression levels of these genes were quantified using real-time PCR (QPCR) in whole hearts (a, d, $\mathbf{g} ; n=6$ per group) as well as in isolated left ventricles of mice (b, e, h; $n=8 ; 3$ months of age) and human donors (c, f, i; $n=3$ for $<40$-year-old women, $n=6$ for

enriched GeneOntology categories, i.e. biological process and molecular function (Table 3 and Supplementary Table 2). We found that genes involved in inflammatory processes and in chemotaxis were overrepresented in both species. Murine genes in these categories were predominantly female-biased (e.g. Sftpd, Ccr7, Ccl7, Ccl25, Ccl28), whereas human genes were detected with male-biased expression (e.g. CCL7, CCL11, CCL22, PLAU, IL8, IL1RN, FOSL1, PTX3). For serpin peptidase inhibitor A3 (SERPINA3/Serpina3n) involved in inflammatory responses, female-biased expression was detected in both species (see Table 1). In addition, genes involved in spermatogenesis were enriched among human sexually dimorphic genes. In terms of $<40$-year-old men, $n=7$ for $50-65$-year-old women and men). Data represent mean values of relative expression levels normalised to the geometric mean of reference gene expression levels (HPRT, GAPDH and $18 \mathrm{~S}) \pm$ SEM. Asterisks indicate levels of significance determined by two-tailed $t$ tests assuming unequal variance of the biological replicates. (Asterisks, $p<0.05$; double asterisk, $p<0.01$ )

molecular function, only gene products with receptor-binding activity represented predominantly by $\mathrm{CD}$ antigens and chemokine ligands were overrepresented in both species.

\section{Discussion}

The identification of sexually dimorphic genes in the healthy individual may provide the necessary basis for a better understanding of the physiological differences between sexes. Consistent with previous findings for other organs [1, 3], we identified only a few autosomal genes with substantial expression differences between sexes (e.g. 

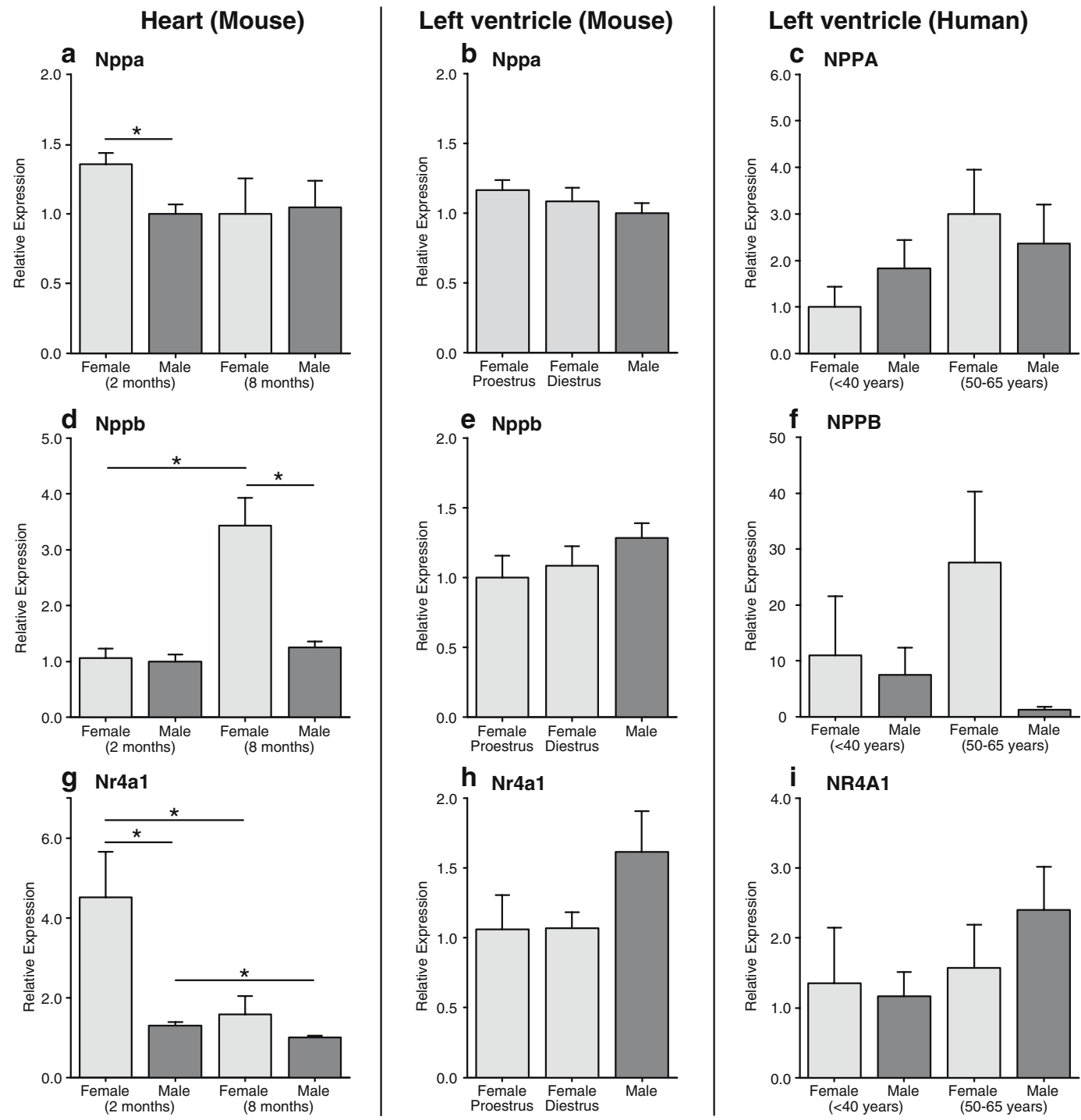

Fig. 4 Analysis of sex-biased gene expression of natriuretic peptide precursor A (Nppa), Nppb and nuclear receptor 4a1 (Nr4a1) in individual samples. The expression levels of these genes were quantified using real-time PCR (QPCR) in whole hearts $(\mathbf{a}, \mathbf{d}, \mathbf{g} ; n=$ 6 per group) as well as in isolated left ventricles of mice (b, e, $\mathbf{h} ; n=8$; 3 months of age) and human donors (c, f, i; $n=3$ for $<40$-year-old

women, $n=6$ for $<40$-year-old men, $n=7$ for $50-65$-year-old women and men). Data represent mean values of relative expression levels normalised to the geometric mean of reference gene expression levels (HPRT, GAPDH and 18S) \pm SEM. Asterisks indicate levels of significance determined by two-tailed $t$ tests assuming unequal variance of the biological replicates. (Asterisks, $p<0.05$; double asterisk, $p<0.01$ )

Car3 and Cyp2b10). Moreover, we found numerous X- and Y-linked genes having sex-specific expression in the heart (e.g. Xist, Ddx3y, and Jarid1d).

To assess whether sexual dimorphisms are tissue specific, we compared the sexual dimorphisms identified in our study in the cardiac samples with those described for other organs (e.g. adipose tissue, kidney, liver, and skeletal muscle; Supplementary Table 3). Although a significant overlap was found, the expression of approximately $40 \%$ of these genes was biased in different directions (i.e. femalebiased in the heart and male-biased in another tissue), suggesting that the mechanisms regulating sex-specific expression may indeed be tissue-specific in the heart, as has been shown before for other organs.
Sex-specific expression of $\mathrm{X}$ - and Y-linked genes

Genes on the Y-chromosome were found being overrepresented in our as well as in the CardioGenomics datasets and may therefore represent the main sexual dimorphism at transcriptional level in the healthy heart. In our study, all sexually dimorphic Y-linked genes are encoded on the Xdegenerated region of the Y-chromosome and have therefore paralogues on the $\mathrm{X}$-chromosome. For the mouse, brain expression of Y-linked genes was reported to be compensated by the expression of X-linked homologues escaping X-chromosomal inactivation $[18,30]$. Indeed, we observed male-specific expression of Y-linked genes (e.g. Eif2s3y and EIF1AY; Ddx3y) as well as female-biased 
Table 2 Overrepresented chromosomes encoding sexually dimorphic genes in the heart of mice and humans

\begin{tabular}{|c|c|c|c|}
\hline Chr. & Percent & $p$ value & Genes \\
\hline \multicolumn{4}{|c|}{ Mouse hearts, 2 months (Agilent) } \\
\hline Y & 3.7 & $7.9 \mathrm{E}-04$ & Eif2s3y, Jarid1d, Ddx3y \\
\hline 6 & 12.4 & $2.5 \mathrm{E}-02$ & Cd4, Cidec, Clstn3, Tcrb-V13, Gys2, Snca, Lrmp, Cd8a \\
\hline \multicolumn{4}{|c|}{ Mouse hearts, 8 months (Agilent) } \\
\hline Y & 9.7 & $9.6 \mathrm{E}-05$ & Eif2s3y, Jarid1d, Ddx3y \\
\hline $\mathrm{X}$ & 12.9 & $5.8 \mathrm{E}-02$ & Gla, Xist, Timp1, Car5b \\
\hline \multicolumn{4}{|c|}{ Human left ventricular myocardium, $<40$ years (Agilent) } \\
\hline Y & 4.4 & $1.7 \mathrm{E}-03$ & EIF1AY, USP9Y, RPS4Y1, SMCY \\
\hline 1 & 16.3 & $8.2 \mathrm{E}-02$ & $\begin{array}{l}\text { NEK7, TNNI1, NPPA, TIE1, CYP2J2, PLA2G2A, CYP4B1, RASSF5, GADD45A, RXRG, } \\
\text { ELF3, IL24, PTGFRN, ATF3, PRELP }\end{array}$ \\
\hline \multicolumn{4}{|c|}{ Human left ventricular myocardium, 50-65 years (Agilent) } \\
\hline Y & 2.5 & $4.0 \mathrm{E}-02$ & EIF1AY, USP9Y, RPS4Y1 \\
\hline 8 & 6.6 & $9.2 \mathrm{E}-02$ & DEFA1, CA3, YWHAZ, TNFRSF11B, MYC, CTSB, LPL, XPO7 \\
\hline \multicolumn{4}{|c|}{ Human left ventricular myocardium, 50 years (Affymetrix) } \\
\hline Y & 61.1 & $7.7 \mathrm{E}-18$ & $\begin{array}{l}\text { DDX3Y, UTY, EIF1AY, PRKY, ZFY, USP9Y, CYorf14, RPS4Y1, CYorf15A, CYorf15B, } \\
\text { SMCY }\end{array}$ \\
\hline
\end{tabular}

Chromosomal localization, percentage of analysed genes and gene names are given (FDR $<5 \%$, fold-change $>2$; Fisher's exact test, $p<0.05$ ). Note that genes on the Y chromosome are enriched in both species and age groups among the genes with sex-biased expression.

expression of their X-linked counterparts (e.g. EIF2S3X, Ddx3x). We also found male-specific expression of several Y-linked genes without female-biased expression of their $\mathrm{X}$-linked homologues (e.g. Jarid1d and Uty), which is consistent with previous findings $[1,3]$ and may indicate that the expression level of some Y-linked genes in somatic tissues is minor compared to that of their X-linked homologues. Furthermore, we found substantially more sexually dimorphic Y-linked genes in the human than in the mouse heart, which reflects an important species-difference. Indeed, as the human Y chromosome is three times bigger in size and encodes almost five times more protein-coding genes than the mouse one, many human genes we found with male-specific expression (e.g. RPS4Y1, PRKY, CYorf14, CYorf15A and CYorf15B) have no murine orthologue on the mouse $\mathrm{Y}$ chromosome.

Besides compensation at the transcriptional level, translational control mechanisms have also been implicated in the expression of Y-linked genes in somatic tissues [31]. For instance, the human DDX3Y gene, which we found being male-specific, is essential for spermatogenesis and is widely transcribed, but protein expression is limited to the male germ cells [31]. In contrast, the protein encoded by the DDX3X gene was found to be expressed ubiquitously. Ddx3 proteins have similarity to RNA helicases and are nucleocytoplasmic shuttling proteins that localise to nuclear membrane pores and facilitate mRNA export [32]. We may therefore assume a different function of the protein encoded by DDX3Y in male germ cells than that of DDX3X in other cell types or tissues. In addition, Y-linked genes involved in the regulation of translation (e.g. RPS4Y1) or in protein degradation (e.g. USP9Y) were also found to be expressed in a male-specific fashion in our study. Interestingly, the human USP9Y mRNA is expressed in a wide range of adult and embryonic tissues, including the testis, whereas the homologous mouse gene is expressed in the testis only [33]. Consistent with these findings we detected USP9Y only in the myocardium of male human donors (Fig. 2c). To what extent, however, sex-biased expression of Y-linked genes has functional consequences for the heart has still to be elucidated.

We found female-specific expression of X-linked genes, including the non-coding RNA Xist, which is associated with X-chromosome allele silencing in females during X inactivation [34-36]. The percentage of mammalian Xlinked genes varies between 3.8 and $4.4 \%$ depending on the species [19]. It has been reported that approximately $15 \%$ of them may escape $\mathrm{X}$ inactivation [20]. We therefore expected to identify several X-linked genes with femalebiased expression in the heart. However and in agreement with previous studies in other organs [3], we only detected a limited number of X-linked genes with female-biased expression (e.g. Gla, Car5b, Timp1 and GPM6B). Notably, GPM6B and TIMP1 were described previously with inconsistent $\mathrm{X}$ inactivation [20]. Furthermore, recent findings demonstrate that escape from $\mathrm{X}$ inactivation might be also compensated by doubling the expression of $\mathrm{X}$-linked genes in somatic tissues of males [19]. Our findings therefore suggest that stringent dosage compensation between sexes may lead to similar expression levels of X-chromosomal genes in the heart of both sexes. As escape from Xinactivation may be associated with maximally twofold up- 
Table 3 GeneOntology categories of genes with sex-biased expression

\begin{tabular}{|c|c|c|c|c|}
\hline \multicolumn{2}{|l|}{ Mouse hearts } & \multicolumn{3}{|l|}{ Human myocardium } \\
\hline 2 months (Agilent) & 8 months (Agilent) & $<40$ years (Agilent) & 50-65 years (Agilent) & 50 years (Affymetrix) \\
\hline \multicolumn{5}{|l|}{ Biological Process } \\
\hline Cation transport & Acute-phase response & Apoptosis & Antigen presentation & Protein biosynthesis \\
\hline $\begin{array}{l}\text { Regulation of signal } \\
\text { transduction }\end{array}$ & Chemotaxis & Cation homeostasis & Base-excision repair & Spermatogenesis \\
\hline Second-messenger signaling & Inflammatory response & Chemotaxis & Cell growth & \\
\hline $\begin{array}{l}\text { Reg. of calcium-mediated } \\
\text { signaling }\end{array}$ & & Fatty acid metabolism & Gas transport & \\
\hline Reg. of immune response & & Humoral immune response & Oxygen transport & \\
\hline Cellular defense response & & Inflammatory response & Regulation of cell size & \\
\hline Chemotaxis & & $\begin{array}{l}\text { Reg. of programmed cell } \\
\text { death }\end{array}$ & & \\
\hline Immune cell activation & & Response to unfolded protein & & \\
\hline Lymphocyte activation & & Response to virus & & \\
\hline Lymphocyte differentiation & & Spermatogenesis & & \\
\hline \multicolumn{5}{|l|}{ Molecular Function } \\
\hline Cation binding & Antigen binding & Receptor binding & $\begin{array}{l}\text { Enzyme inhibitor } \\
\text { activity }\end{array}$ & RNA binding \\
\hline Receptor binding & $\begin{array}{l}\text { Carbonate dehydratase } \\
\text { act. }\end{array}$ & DNA binding & $\begin{array}{l}\text { Unfolded protein } \\
\text { binding }\end{array}$ & Nucleic acid binding \\
\hline MHC protein binding & Chitinase activity & Protein binding & $\begin{array}{l}\text { Struct. molecule } \\
\text { activity }\end{array}$ & \\
\hline \multirow[t]{6}{*}{ Hydro-lyase activity } & Hydrolase activity & Signal transducer activity & Actin binding & \\
\hline & & Cytokine activity & $\begin{array}{l}\text { Cytoskel. protein } \\
\text { binding }\end{array}$ & \\
\hline & & Chemokine activity & Heme binding & \\
\hline & & & Tetrapyrrole binding & \\
\hline & & & Oxygen transp. activity & \\
\hline & & & Oxygen binding & \\
\hline
\end{tabular}

Genes were annotated according to their biological process and molecular function and analysed for their significant enrichment (FDR $<5 \%$, foldchange $>2$; Fisher's exact test, $\mathrm{p}<0.05$ ). Gene categories enriched in more than one group are highlighted in bold (e.g. inflammatory response and spermatogenesis as well as receptor binding). A detailed list of all enriched pathways and associated $p$ values is provided in Supplementary Table 2.

regulation of gene expression, numerous biological replicates will be necessary in the future to quantify reliably the percentage of $\mathrm{X}$-linked genes affected by $\mathrm{X}$ inactivation.

Growth hormone influences sex-biased gene expression

Several studies have demonstrated that the sex-specific pattern of GH release is a major mechanistic determinant of sexually dimorphic gene expression in the rodent liver [2, 17, 37]. A recent study showed that administration of GH with a malespecific pattern to female mice resulted in the repression of female-predominant genes (e.g. Cyp2b10) and in the induction of male-specific ones [17]. Accordingly, we detected female-biased expression of Cyp2b10 (Fig. 3g, h). Although fold-changes were smaller in the left ventricle than in the whole heart, this difference might be explained by a predominant expression of Cyp2b10 in the right ventricle, as it has been shown for its human orthologue CYP2B6 [38]. Cyp2b10 expression increases significantly in the hearts of mice during aging and a similar trend was observed in humans (Fig. 3g, i), suggesting that lower GH levels in older organisms may be associated with a higher expression of Cyp2b10 as well as a common age-dependent mechanism of GH in both species. Indeed, higher expression levels of Cyp $2 b$ family members were detected in the hypopituitary GH-deficient long-lived Ames, Little and Snell dwarf mice $[39,40]$. As Cyp2b enzymes turn over a broad range of substrates including steroids, fatty acids and xenobiotics, sex-biased expression levels of these enzymes are likely to be involved in different drug metabolism observed between men and women.

Other genes eventually regulated by sex-specific GH patterns are carbonic anhydrases. They catalyse the reversible hydration of carbon dioxide and participate in a variety of biological processes, e.g. respiration, calcification, acidbase balance and bone resorption [41]. We identified carbonic anhydrases Car2, Car3 and Car5b with femalebiased expression in the heart of either mice and/or human 
donors (Figs. 2 and $3 \mathrm{a}-\mathrm{f}$ ), and similar findings have been reported for adipose tissue as well as for skeletal muscle (Supplementary Table 3). In contrast, Car3 gene expression as well as protein activity have been shown to be malepredominant in the liver of rodents [3, 42], suggesting tissue-specific mechanisms in the sex-specific regulation of Car3 expression. As we observed for Cyp2b10, the expression levels of Car2 also seem to be associated with age (Fig. 3d,f).

Sex steroid hormones may influence gene expression in the heart

To compare gene expression patterns of healthy male and female cardiac samples may represent a first step towards identifying sex steroid hormone-responsive genes in the heart. Lactotransferrin (Ltf) is a well-known estrogen receptor target gene containing estrogen responsive elements in the promoter and its expression has been shown to be regulated in the uterus during the oestrous cycle [43]. In our study we not only detected Ltf being upregulated in females (Fig. 2), but its expression in individual whole hearts correlates with that of other genes such as steroid $15 \alpha$-hydroxylase (Cyp2a4, Pearson-coefficient $r=0.92$ ) and Cyp2f2 (Pearson-coefficient $r=0.93$ ). Therefore, we assumed that the oestrous cycle might be an important modifier of gene expression in the heart as it has been shown for the uterus [44]. However, we could not detect expression of these genes in isolated left ventricles of females at defined stages of the oestrous cycle. Therefore chamber-specific expression cannot be excluded and further investigations will be necessary.

Chamber-specific and/or species-specific differences in gene expression might also account for the female-biased expression of the orphan nuclear receptor Nr4al (Nurr77, NGFI-B), which could only be detected in the whole heart of mice (Figs. 2 and 4). As Nr4al is a functional transcription factor that binds DNA in the absence of a ligand [45] and is involved in several key biological processes including gene expression regulation in the hypothalamic-pituitary adrenal axis [46], it may still represent a valuable candidate gene for the regulation of sex-specific differences in the rodent heart.

Sexual dimorphisms in the context of cardiovascular disease

The basis of sex-specific gene expression in the adult healthy heart may be relevant for a better understanding of the gender-specific aspects of human cardiovascular disease. Indeed, a study screening for human heart failure responsive genes revealed that the expression of most candidate genes was affected by age and/or sex [47]. We identified orosomucoid 1 in the healthy heart of mice as well as FK506 binding protein 5, integrin beta 1 and osteoblast-specific factor 2 in human donors with femalepredominant expression. Notably, Weinberg et al. [48] had described these genes to be up-regulated in males and down-regulated in females upon pressure overload in a mouse model for left ventricular hypertrophy. Some of these genes are involved in immune and inflammatory responses and intriguingly, we found these GO categories being enriched in the heart as well (Table 3 and Supplementary Table 2) reflecting the striking differences between sexes regarding the immune system. Although these findings may substantiate the relevance of sex-specific gene expression in the healthy heart, to what extent and with what consequences sex-biased gene expression in the healthy condition is kept during disease has still to be elucidated. Such a comparative analysis was not possible here, as most human data were generated from male donors or samples not arranged with a gender focus.

Jarid1d (also known as SMCY, selected mouse cDNA on the $Y$ ) is a member of the ARID family that contains DNAbinding motifs and was detected with male-specific expression in both species in our study. As it encodes a male-specific transplantation antigen defined by an octamer peptide not encoded by the X-linked homologue (SMCX, Jarid1c), it is presumably involved in the genetic basis of the antigenic differences between males and females [49]. Interestingly, the related ARID family member Jarid2 was found to repress atrial natriuretic factor (ANF) expression during heart development by inhibiting the transcriptional activity of Nkx2.5 and GATA4 [50]. Although the functional role of ARID family members has still to be analyzed, they may play an important role in basic cardiac physiology.

Natriuretic peptide precursor B (BNP) is not only considered a well-known prognostic marker for acute and chronic coronary disease, but also higher plasma levels of BNP in women as well as in aged patients have been demonstrated in clinical studies [29, 51]. In our study we observed no sex-related differences in BNP expression in young mice, but a significant sexual dimorphism in 8 months old ones. Accordingly, higher BNP transcript levels were detected in the heart of aged women, agreeing with the concept that the strongest predictors of high BNP levels are age and female sex.

Altogether, we provide a first insight into the sex-specific gene expression patterns of the heart of healthy mice and human donors. In future studies, more time points will have to be considered to distinguish between individuals at childhood, puberty, adulthood and senescence as well as comparable whole-genome covering microarray platforms for both species. In addition, the use of synchronised females may allow the identification of more estrogen-responsive 
genes to elucidate the complex actions of female sex hormones onto the cardiovascular system. This represents a challenging task especially in humans, as a higher biological variability will require the analysis of a large number of individuals. We would furthermore like to underline the importance of combining genome-wide expression profiling with proteomics approaches. In summary, our study suggests that sex and age represent important modifiers of gene expression in the mammalian heart and provides a basis for the analysis of gender-specific mechanisms involved in cardiac function.

Acknowledgements We thank Dr. Ute Ungethüm (Center for Functional Genomics, Charité Universitätsmedizin Berlin) for assistance in microarray scanning and Aydah Sabah and Carola Geiler for excellent technical assistance.

\section{References}

1. Rinn JL, Rozowsky JS, Laurenzi IJ, Petersen PH, Zou K, Zhong W, Gerstein M, Snyder M (2004) Major molecular differences between mammalian sexes are involved in drug metabolism and renal function. Dev Cell 6:791-800

2. Ahluwalia A, Clodfelter KH, Waxman DJ (2004) Sexual dimorphism of rat liver gene expression: regulatory role of growth hormone revealed by deoxyribonucleic acid microarray analysis. Mol Endocrinol 18:747-760

3. Yang X, Schadt EE, Wang S, Wang H, Arnold AP, Ingram-Drake L, Drake TA, Lusis AJ (2006) Tissue-specific expression and regulation of sexually dimorphic genes in mice. Genome Res 16:995-1004

4. Rinn JL, Snyder M (2005) Sexual dimorphism in mammalian gene expression. Trends Genet 21:298-305

5. Hayward CS, Kelly RP, Collins P (2000) The roles of gender, the menopause and hormone replacement on cardiovascular function. Cardiovasc Res 46:28-49

6. Mendelsohn ME, Karas RH (2005) Molecular and cellular basis of cardiovascular gender differences. Science 308:1583-1587

7. Regitz-Zagrosek V (2006) Therapeutic implications of the genderspecific aspects of cardiovascular disease. Nat Rev Drug Discov 5:425-439

8. McKenna NJ, O'Malley BW (2002) Combinatorial control of gene expression by nuclear receptors and coregulators. Cell 108:465-474

9. Bjornstrom L, Sjoberg M (2005) Mechanisms of estrogen receptor signaling: convergence of genomic and nongenomic actions on target genes. Mol Endocrinol 19:833-842

10. Edwards DP (2005) Regulation of signal transduction pathways by estrogen and progesterone. Annu Rev Physiol 67:335-376

11. van Eickels M, Grohe C, Cleutjens JP, Janssen BJ, Wellens HJ, Doevendans PA (2001) 17beta-estradiol attenuates the development of pressure-overload hypertrophy. Circulation 104:1419-1423

12. Gabel SA, Walker VR, London RE, Steenbergen C, Korach KS, Murphy E (2005) Estrogen receptor beta mediates gender differences in ischemia/reperfusion injury. J Mol Cell Cardiol 38:289-297

13. Pare G, Krust A, Karas RH, Dupont S, Aronovitz M, Chambon P, Mendelsohn ME (2002) Estrogen receptor-alpha mediates the protective effects of estrogen against vascular injury. Circ Res 90:1087-1092

14. Egan KM, Lawson JA, Fries S, Koller B, Rader DJ, Smyth EM, Fitzgerald GA (2004) COX-2-derived prostacyclin confers atheroprotection on female mice. Science 306:1954-1957
15. Xin HB, Senbonmatsu T, Cheng DS, Wang YX, Copello JA, Ji GJ, Collier ML, Deng KY, Jeyakumar LH, Magnuson MA, Inagami T, Kotlikoff MI, Fleischer S (2002) Oestrogen protects FKBP12.6 null mice from cardiac hypertrophy. Nature 416:334-338

16. Udy GB, Towers RP, Snell RG, Wilkins RJ, Park SH, Ram PA, Waxman DJ, Davey HW (1997) Requirement of STAT5b for sexual dimorphism of body growth rates and liver gene expression. Proc Natl Acad Sci U S A 94:7239-7244

17. Jarukamjorn K, Sakuma T, Jaruchotikamol A, Ishino Y, Oguro M, Nemoto N (2006) Modified expression of cytochrome P450 mRNAs by growth hormone in mouse liver. Toxicology 219:97-105

18. Xu J, Burgoyne PS, Arnold AP (2002) Sex differences in sex chromosome gene expression in mouse brain. Hum Mol Genet 11:1409-1419

19. Nguyen DK, Disteche CM (2006) Dosage compensation of the active $X$ chromosome in mammals. Nat Genet 38:47-53

20. Carrel L, Willard HF (2005) X-inactivation profile reveals extensive variability in $\mathrm{X}$-linked gene expression in females. Nature 434:400-404

21. Skaletsky H, Kuroda-Kawaguchi T, Minx PJ, Cordum HS, Hillier L, Brown LG, Repping S, Pyntikova T, Ali J, Bieri T, Chinwalla A, Delehaunty A, Delehaunty K, Du H, Fewell G, Fulton L, Fulton R, Graves T, Hou SF, Latrielle P, Leonard S, Mardis E, Maupin R, McPherson J, Miner T, Nash W, Nguyen C, Ozersky P, Pepin K, Rock S, Rohlfing T, Scott K, Schultz B, Strong C, Tin-Wollam A, Yang SP, Waterston RH, Wilson RK, Rozen S, Page DC (2003) The male-specific region of the human $Y$ chromosome is a mosaic of discrete sequence classes. Nature 423:825-837

22. Nelson JF, Felicio LS, Randall PK, Sims C, Finch CE (1982) A longitudinal study of estrous cyclicity in aging C57BL/6J mice: I. Cycle frequency, length and vaginal cytology. Biol Reprod 27:327-339

23. Tusher VG, Tibshirani R, Chu G (2001) Significance analysis of microarrays applied to the ionizing radiation response. Proc Natl Acad Sci U S A 98:5116-5121, Epub 2001 Apr 17

24. Dennis G Jr, Sherman BT, Hosack DA, Yang J, Gao W, Lane HC, Lempicki RA (2003) DAVID: database for annotation, visualization, and integrated discovery. Genome Biol 4:P3

25. Hosack DA, Dennis G, Jr., Sherman BT, Lane HC, Lempicki RA (2003) Identifying biological themes within lists of genes with EASE. Genome Biol 4:R70, Epub 2003 Sep 11

26. Peirson SN, Butler JN, Foster RG (2003) Experimental validation of novel and conventional approaches to quantitative real-time PCR data analysis. Nucleic Acids Res 31:e73

27. Vandesompele J, De Preter K, Pattyn F, Poppe B, Van Roy N, De Paepe A, Speleman F (2002) Accurate normalization of real-time quantitative RT-PCR data by geometric averaging of multiple internal control genes. Genome Biol 3:RESEARCH0034

28. Rozen S, Skaletsky H (2000) Primer3 on the WWW for general users and for biologist programmers. Methods Mol Biol 132:365-386

29. Waku S, Iida N, Ishihara T (2000) Significance of brain natriuretic peptide measurement as a diagnostic indicator of cardiac function. Methods Inf Med 39:249-253

30. Xu J, Watkins R, Arnold AP (2006) Sexually dimorphic expression of the X-linked gene Eif2s3x mRNA but not protein in mouse brain. Gene Expr Patterns 6:146-155, Epub 2005 Dec 1

31. Ditton HJ, Zimmer J, Kamp C, Rajpert-De Meyts E, Vogt PH (2004) The AZFa gene DBY (DDX3Y) is widely transcribed but the protein is limited to the male germ cells by translation control. Hum Mol Genet 13:2333-2341, Epub 2004 Aug 4

32. Yedavalli VS, Neuveut C, Chi YH, Kleiman L, Jeang KT (2004) Requirement of DDX3 DEAD box RNA helicase for HIV-1 RevRRE export function. Cell 119:381-392

33. Brown GM, Furlong RA, Sargent CA, Erickson RP, Longepied G, Mitchell M, Jones MH, Hargreave TB, Cooke HJ, Affara NA 
(1998) Characterisation of the coding sequence and fine mapping of the human DFFRY gene and comparative expression analysis and mapping to the Sxrb interval of the mouse Y chromosome of the Dffry gene. Hum Mol Genet 7:97-107

34. Brown CJ, Ballabio A, Rupert JL, Lafreniere RG, Grompe M, Tonlorenzi R, Willard HF (1991) A gene from the region of the human $\mathrm{X}$ inactivation centre is expressed exclusively from the inactive X chromosome. Nature 349:38-44

35. Penny GD, Kay GF, Sheardown SA, Rastan S, Brockdorff N (1996) Requirement for Xist in $\mathrm{X}$ chromosome inactivation. Nature 379:131-137

36. Panning B, Dausman J, Jaenisch R (1997) X chromosome inactivation is mediated by Xist RNA stabilization. Cell 90:907-916

37. Clodfelter KH, Holloway MG, Hodor P, Park SH, Ray WJ, Waxman DJ (2006) Sex-dependent liver gene expression is extensive and largely dependent upon signal transducer and activator of transcription 5b (STAT5b): STAT5b-dependent activation of male genes and repression of female genes revealed by microarray analysis. Mol Endocrinol 20:1333-1351

38. Thum T, Borlak J (2000) Gene expression in distinct regions of the heart. Lancet 355:979-983

39. Amador-Noguez D, Yagi K, Venable S, Darlington G (2004) Gene expression profile of long-lived Ames dwarf mice and Little mice. Aging Cell 3:423-441

40. Boylston WH, DeFord JH, Papaconstantinou J (2006) Identification of longevity-associated genes in long-lived Snell and Ames dwarf mice. AGE 28:125-144

41. Dodgson SJ, Tashian RE, Gross G, Carter ND (1991) The carbonic anhydrases: cellular physiology and molecular genetics. Plenum, New York

42. Shiels A, Jeffery S, Phillips IR, Shephard EA, Wilson CA, Carter ND (1983) Sexual differentiation of rat liver carbonic anhydrase III. Biochim Biophys Acta 760:335-342
43. Teng CT (2002) Lactoferrin gene expression and regulation: an overview. Biochem Cell Biol 80:7-16

44. Tan YF, Li FX, Piao YS, Sun XY, Wang YL (2003) Global gene profiling analysis of mouse uterus during the oestrous cycle. Reproduction 126:171-182

45. Wilson TE, Fahrner TJ, Johnston M, Milbrandt J (1991) Identification of the DNA binding site for NGFI-B by genetic selection in yeast. Science 252:1296-1300

46. Bassett MH, White PC, Rainey WE (2004) A role for the NGFI-B family in adrenal zonation and adrenocortical disease. Endocr Res 30:567-574

47. Boheler KR, Volkova M, Morrell C, Garg R, Zhu Y, Margulies K, Seymour AM, Lakatta EG (2003) Sex- and age-dependent human transcriptome variability: implications for chronic heart failure. Proc Natl Acad Sci USA 100:2754-2759

48. Weinberg EO, Mirotsou M, Gannon J, Dzau VJ, Lee RT, Pratt RE (2003) Sex dependence and temporal dependence of the left ventricular genomic response to pressure overload. Physiol Genomics 12:113-127

49. Scott DM, Ehrmann IE, Ellis PS, Bishop CE, Agulnik AI, Simpson E, Mitchell MJ (1995) Identification of a mouse malespecific transplantation antigen, H-Y. Nature 376:695-698

50. Kim TG, Chen J, Sadoshima J, Lee Y (2004) Jumonji represses atrial natriuretic factor gene expression by inhibiting transcriptional activities of cardiac transcription factors. Mol Cell Biol 24:10151-10160

51. Maisel AS, Clopton P, Krishnaswamy P, Nowak RM, McCord J, Hollander JE, Duc P, Omland T, Storrow AB, Abraham WT, Wu AH, Steg G, Westheim A, Knudsen CW, Perez A, Kazanegra R, Bhalla V, Herrmann HC, Aumont MC, McCullough PA (2004) Impact of age, race, and sex on the ability of B-type natriuretic peptide to aid in the emergency diagnosis of heart failure: results from the Breathing Not Properly (BNP) multinational study. Am Heart J 147:1078-1084 